\title{
Investigation of Interleukin-17 Gene-152g/A Polymorphism and IL-17 Serum Levels in Patients with Cardiac Syndrome X
}

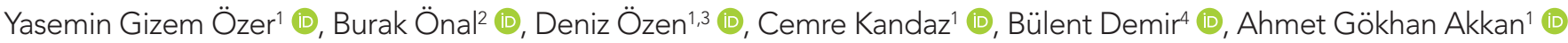 \\ 1Department of Medical Pharmacology, İstanbul University Cerrahpaşa, Cerrahpaşa School of Medicine, İstanbul, Turkey \\ ${ }^{2}$ Department of Medical Pharmacology, Biruni University School of Medicine, İstanbul, Turkey \\ ${ }^{3}$ Department of Molecular Biology and Genetics, İstinye University School of Letters, İstanbul, Turkey \\ ${ }^{4}$ Department of Cardiology, University of Health Sciences, Bakırköy Dr. Sadi Konuk Training and Research Hospital, İstanbul, Turkey \\ Cite this article as: Özer YG, Önal B, Özen D, Kandaz C, Demir B, Akkan AG. Investigation of Interleukin-17 Gene-152g/A Polymorphism and IL-17 \\ Serum Levels in Patients with Cardiac Syndrome X. JAREM 2019; 9(Supplement 1): S23-8.
}

\begin{abstract}
Objective: Cardiac syndrome X (CSX) can be defined as experiencing chest pain with angina by patients with normal coronary arteries. Endothelial and microvascular dysfunction is responsible for the pathophysiology of the inflammatory CSX disease. Inflammation is especially an important factor in the progression of ischemic heart diseases. It is accepted that both the number of B and T lymphocytes and expression of various proinflammatory cytokines released from those cells increases during inflammatory response. Different proinflammatory cytokines are produced by activated macrophages and T lymphocytes. Since interleukin-17 (IL-17) induces many signaling molecules, which promote immune response and play a role in inflammation, it is assumed that IL-17 can play a role in the CSX pathogenesis. In our study, the relationship between CSX and IL-17 serum levels and the -152G/A polymorphism on IL-17 gene was investigated.

Methods: Serum IL-17 levels of blood samples were analyzed from 100 patients with CSX and 101 healthy control individuals using the EnzymeLinked ImmunoSorbent Assay (ELISA) method. After the DNA isolation was performed from blood samples, the IL-17 gene-152G/A polymorphisms were detected based on the PCR-RFLP method for both patients and healthy individuals. The pomotor region of the IL-17 gene was amplified by the PCR method, and then, genotyping was performed using PCR products for the RFLP step. After that, obtained data for CSX patients and the healthy control group were compared using the statistical analysis.

Results: When the IL-17 gene-152G/A polymorphism genotyping results of patients with CSX and healthy control individuals were compared, no statistically significant difference was observed in both genotypic and allelic distributions $(p=0.218)$. The IL-17 serum levels were found to be significantly higher in patients with CSX than in healthy controls $(p<0.001)$.

Conclusion: Endothelium plays a significant role in the regulation of vascular functions. Inflammatory response is generated against the endothelial activation in the CSX pathogenesis. An increase in the CRP levels, which is a marker of inflammation, is common for both coronary artery disease and CSX, associated with endothelial dysfunction. Helper T cells play important roles in cardiovascular diseases. IL-17 induces the expression of different proinflammatory cytokines and chemokines, participating in the tissue infiltration and destruction. There are also several studies that prove the significant role of proinflammatory IL-17, which is released from T cells, in cardiovascular diseases, supporting our results. In addition, it has been demonstrated that statins, having anti-inflammatory effects, inhibit the IL-17 gene expression and cytokine release. In this context, we foresee that statins can have a subsidiary effect on the CSX treatment to suppress the inflammatory response in patients in who the IL-17 levels were determined as significantly higher than in healthy controls.
\end{abstract}

Keywords: Cardiac Syndrome X, inflammation, endothelial dysfunction, IL-17, -152G/A polymorphism

ORCID IDs of the authors: Y.G.Ö. 0000-0003-1107-8623; B.Ö. 0000-0002-7846-875X; D.Ö. 0000-0002-3095-1208; C.K. 0000-0002-0589-7465; B.D. 00000003-3252-5218; A.G.A. 0000-0003-3210-2709. 


\section{INTRODUCTION}

Although cardiac syndrome $X$ (CSX) is used to describe a group of patients with typical exercise-induced chest pain and normal coronary arteries, the consensus on the definitive diagnosis of the disease has yet to be reached in the guidelines. The reason for this is that the syndrome is heterogeneous and contains many different pathological mechanisms (1). Microvascular dysfunction is predominantly responsible for the pathogenesis of CSX. In several studies, it has been shown that there is increased chest pain perception in patients with angina with normal coronary arteries; however, it is not yet clear whether there is a cardiac problem at the origin of this pain. Microvascular dysfunction in CSX may be due to multiple mechanisms that are not expected to be the same in all patients (2).

Immunopathology and inflammation are thought to play important roles in the onset and progression of ischemic heart diseases. In atherosclerotic dysfunction, leukocytes, such as monocytes/macrophages, T cells, and B cells were found to increase in amount (3). Endothelial cells of normal structure are resistant to adhesion of leukocytes. However, when inflammation begins, the expression of selectin family molecules increases on the surface of endothelial cells. These molecules mediate the adhesion of monocytes to endothelial cells. Monocytes adhering to the endothelial cell surface pass into intima and transform into macrophages. Thus, fatty lines, which are the early forms of atherosclerotic lesion, are formed from lipid-laden macrophages or foam cells (4).

Although various proinflammatory cytokines are produced by activated macrophages and $T$ lymphocytes, it has been reported that cytokines are also secreted from adipocytes (5). Interleukin (IL)-17 has a definite proinflammatory property because it induces several signal molecules and it is thought to take a role in the pathogenesis of CSX since inflammation plays an important role in in its pathophysiology (6). IL-17 causes the production of cytokines, such as IL-6, granulocyte colony stimulating factor (CSF), granulocyte-macrophage CSF, IL-1 $\beta$, transforming growth factor- $\beta$, and tumor necrosis factor (TNF)- $\alpha$, keratinocytes, such as IL-8, growth-regulated oncogene- $\alpha$, and monocyte chemoattractant protein-1, and prostaglandins, such as prostaglandin E2, in many different types of cells, such as fibroblasts, endothelial cells, keratinocytes, and macrophages. The expression of each member of the IL-17 family is different from each other. The expressions of IL-17A and IL-17F are observed only in a small number of activated $\mathrm{T}$ cells and are regulated during inflammation (7).

The aim of the present study was to target the IL-17 gene -152G/ A polymorphism and IL-17 serum levels that are thought to play a role in the pathophysiology of CSX and to explain the relationship between inflammation and disease on a genetic basis.

\section{METHODS}

This study was approved by the ethics committee for clinical research within our faculty (approval no.: 35453) and conducted in accordance with the Helsinki Declaration issued by the World Medical Association. The patients and control subjects who signed the informed consent form were included in the study.
A total of 100 consecutive patients with CSX diagnosed in the cardiology clinic of our hospital according to the 2013 European Society of Cardiology Guidelines for Stable Coronary Disease Management (8) and a control group of 101 asymptomatic healthy individuals with similar age and gender characteristics with a 10 -year probability of $<10 \%$ cardiac event according to the Framingham Risk Score were included in the study. The exclusion criteria included coronary artery disease, previous acute coronary syndrome, slow coronary flow syndrome, coronary artery ectasia, vasospastic angina, myocardial bridge findings in coronary angiography, congestive heart failure, valvular heart disease, cardiomyopathies, congenital heart disease, pericardial and myocardial diseases, atrial fibrillation block, pulmonary embolism, previous cerebrovascular event, active infection, neoplasia, autoimmune diseases, hepatic dysfunction, and renal dysfunction (serum creatinine level $>1.5 \mathrm{mg} / \mathrm{dL}$ ).

\section{Blood Collection and DNA Isolation}

Blood samples collected from the patients and control subjects via the antecubital vein into K3EDTA tubes after $12 \mathrm{~h}$ of fasting were stored at $-20^{\circ} \mathrm{C}$. Genomic DNA isolation from blood samples was performed using the Invitrogen PureLink Genomic DNA kit (K1820-02; Thermo Fisher, Carlsbad, CA, USA) according to the manufacturer's protocol. Then, A260/A280 optical density (OD) values of isolated DNAs were determined by measuring at 260 and $280 \mathrm{~nm}$ wavelengths with Thermo Scientific NanoDrop 2000 (Carlsbad, CA, USA), and these values were between 1.8 and 0.2 and DNA concentrations were $75-180 \mathrm{ng} / \mathrm{\mu L}$. The obtained genomic DNA samples were stored at $-20^{\circ} \mathrm{C}$ until used for genotyping.

\section{PCR and Genotyping}

In the present study, the polymerase chain reaction (PCR) method was used to determine the -152G/A polymorphism on the promoter region of the IL-17 gene (Applied Biosystems 2720; Applied Biosystems, Foster City, CA, USA). The first denaturation stage of the PCR cycle is $5 \mathrm{~min}$ at $94^{\circ} \mathrm{C}$, then 35 cycles of denaturation, primer binding, and elongation steps were set as $94^{\circ} \mathrm{C}$ for $20 \mathrm{~s}, 60^{\circ} \mathrm{C}$ for $40 \mathrm{~s}$, and $72^{\circ} \mathrm{C}$ for $30 \mathrm{~s}$, respectively. The following process ended with the last elongation for $5 \mathrm{~min}$ at $72{ }^{\circ} \mathrm{C}$. The primer sequences used to amplify the 344 bp region of the IL-17 gene containing the target polymorphism in the promoter region are shown in Table 1. PCR products obtained at the end of the process were run on $1.5 \%$ agarose gels and were observed under ultraviolet to check whether the desired products were formed.

Then, obtained PCR products were cut with Xmnl restriction enzyme using the Restriction Fragment Length Polymorphism (RFLP) method for genotyping. The cut products were run on $2 \%$ agarose gel and analyzed.

\section{ELISA}

Peripheral blood samples were centrifuged at $5000 \mathrm{rpm}$ for $5 \mathrm{~min}$ to obtain blood serum. IL-17 serum levels in the samples were determined using the eBioscience Platinum ELISA kit (Thermo Fisher).

\section{Statistical Analysis}

Data were analyzed using the Statistical Package for Social Sciences version 20.0 (IBM Corp., Armonk, NY, USA) statistical soft- 
ware program for statistical analysis. The summary data were presented as average $\pm \mathrm{SD}$ and percentage. T-test was used to compare the quantitative values of independent groups, and chisquare test was used to compare the categorical characteristics. A two-way ANOVA test was used for quantitative data and subgroup comparisons of the two characteristics. A $p$ value $<0.05$ was accepted as statistically significant.

\section{RESULTS}

\section{Detection of the IL-17 gene -152G/A Polymorphism}

In the present study, the IL-17 gene promoter region was amplified from the genomic DNAs of patients with CSX and control subjects via PCR using the appropriate primers. The products obtained as a result of PCR were visualized by agarose gel electrophoresis method, and it was confirmed that the desired result was obtained (Figure 1)

To determine the $-152 \mathrm{G} / \mathrm{A}$ polymorphism in the promoter region, 344 bp length DNA fragments amplified were cut using $\mathrm{Xmnl}$ restriction enzyme. As a result of the restriction, the samples showing $213 \mathrm{bp}$ and $131 \mathrm{bp}$ length bands were determined as AA genotypes, the samples showing a single band of 344 bp length without restriction were determined as GG genotypes, and the samples with bands of 344, 213, and 131 bp lengths were determined as AG genotypes. Xmnl restriction products of some samples belonging to the patients and control individuals are shown in Figure 2.

The distribution rates of genotypes determined were found to be $20.0 \%$ for $A A, 37.0 \%$ for $A G$, and $43.0 \%$ for $G G$ in patients with CSX; in the control group, AA was found to be $11.9 \%$, AG was $35.6 \%$, and GG was $52.5 \%$ (Table 2). No statistically significant difference was found between the patients and control groups with respect to the genotype distribution of the IL-17 gene-152G/A polymorphism ( $p>0.05$ ) (Table 2). At the same time, there was no significant difference between patients with CSX and control groups with respect to allelic distribution of the IL-17 gene -152G/A polymorphism ( $p>0.05$ ) (Table 3).

\section{IL-17 Serum Level Results}

IL-17 serum levels were determined by the ELISA method. While the average IL-17 serum level of the CSX patient group was $16.39 \pm 6.21 \mathrm{pg} / \mathrm{mL}$, this value was measured as $9.07 \pm 3.35$ $\mathrm{pg} / \mathrm{mL}$ in the control group (Figure 3). When the serum IL-17 levels of the patient and control groups were compared, the IL-17 levels of the patient group were found to be significantly higher $(p<0.001)$.

\section{Demographic Data Results}

When patients with CSX and control subjects included in the study were compared, the incidence of CSX in females was significantly higher than that in the control group $(p<0.05)$. In addition, smoking was found to be significantly higher, and the presence of hypertension and diabetes was higher in patients with CSX than in control subjects. When the use of angiotensin receptor blocker/angiotensin receptor inhibitor, cardiovascular disease, or myocardial infarction or sudden death of first-degree relatives in males before aged 55 years and in females before aged 65 years were compared between the two groups, it was statistically higher in the patient group $(p<0.05)$.
Exercise stress test positivity was found to be $62 \%$ in the patient group, whereas it was $0 \%$ in the control group. Hemoglobin levels were found to be significantly lower in patients with CSX than in the control group. In addition, in the comparison of demographic data of both groups, body mass index, calcium channel blocker and statin usage, platelet, mean platelet volume, aspar-

Table 1. The primers used in the PCR procedure for the amplification of the target region

\begin{tabular}{|l|l|l|}
\hline Gene & Primers & PCR product \\
\hline IL-17 & 5' CAG AAG ACC TAC ATG TTA CT 3' & 344 bp \\
\hline & 5' GTA GCG CTA TCG TCT CTC T 3' & \\
\hline
\end{tabular}

Table 2. The genotype distribution of the IL-17 gene -152G/A polymorphism in patients with CSX and control subjects

\begin{tabular}{|l|c|c|c|}
\hline $\begin{array}{l}\text { IL-17 } \\
\text { promoter }\end{array}$ & $\begin{array}{c}\text { Control, } \\
\mathbf{n}(\%)\end{array}$ & $\begin{array}{c}\text { Patient, } \\
\mathbf{n}(\%)\end{array}$ & $\begin{array}{c}\text { Total, } \\
\mathbf{n}(\%)\end{array}$ \\
\hline AA & $12(11.9)$ & $20(20.0)$ & $32(15.9)$ \\
\hline AG & $36(35.6)$ & $37(37.0)$ & $73(36.3)$ \\
\hline GG & $53(52.5)$ & $43(43.0)$ & $96(47.8)$ \\
\hline Total & $101(100.0)$ & $100(100.0)$ & $201(100.0)$ \\
\hline$p=0.218, \chi^{2}=3.050$, and no significant difference was found. \\
\hline
\end{tabular}

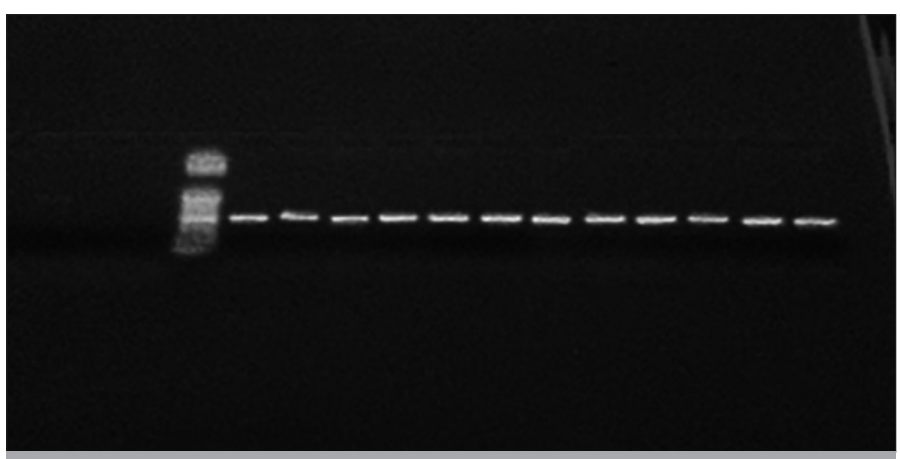

Figure 1. IL-17 gene promoter region PCR products shown on agarose gel electrophoresis. The first well is a molecular weight marker; other 12 wells are PCR products of $344 \mathrm{bp}$ PCR: polymerase chain reaction

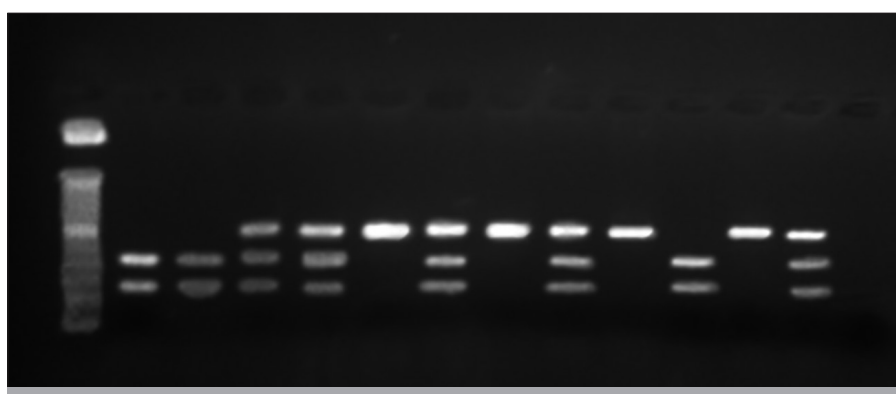

Figure 2. The restricted products of the IL-17 gene cut by the restriction enzyme Xmnl. The first well is the molecular weight indicator; in the $2^{\text {nd }}$ and $3^{\text {rd }}$ wells, AA genotypes with 131 and $213 \mathrm{bp}$ bands, in the $4^{\text {th }}$ and $5^{\text {th }}$ wells, AG genotypes with 344,213 , and 131 bp bands, and in the $6^{\text {th }}$ well, GG genotype with a single band of 344 bp are seen 
tate aminotransferase, alanine aminotransferase, triglyceride, gamma-glutamyl transferase, and total cholesterol low-density lipoprotein and high-density lipoprotein did not have a statistically significant difference (Table 4).

\section{DISCUSSION}

Cardiac syndrome $X$, in addition to having angina pectoris and ST segment depression indicating myocardial ischemia during exercise stress test, is characterized by normal coronary angiography. CSX is thought to be equivalent to microvascular angina due to microcirculatory disorders seen in some patients. Deterioration of vasodilatation at the microvascular level, therefore, endothelial dysfunction, is considered to play an important role in myocardial ischemia and the pathogenesis of angina in patients with $\operatorname{CSX}(9,10)$. Endothelial dysfunction, which is an indicator of endothelial activation, also creates a proinflammatory, proliferative, and procoagulant environment (11). The elevation of the C-reactive protein (CRP) levels, an indicator of inflammation, is a common marker for coronary artery disease and CSX associated with endothelial dysfunction (12).

Helper $\mathrm{T}$ cell responses are of great importance in cardiovascular diseases (3). Any stimulus initiates inflammation by triggering

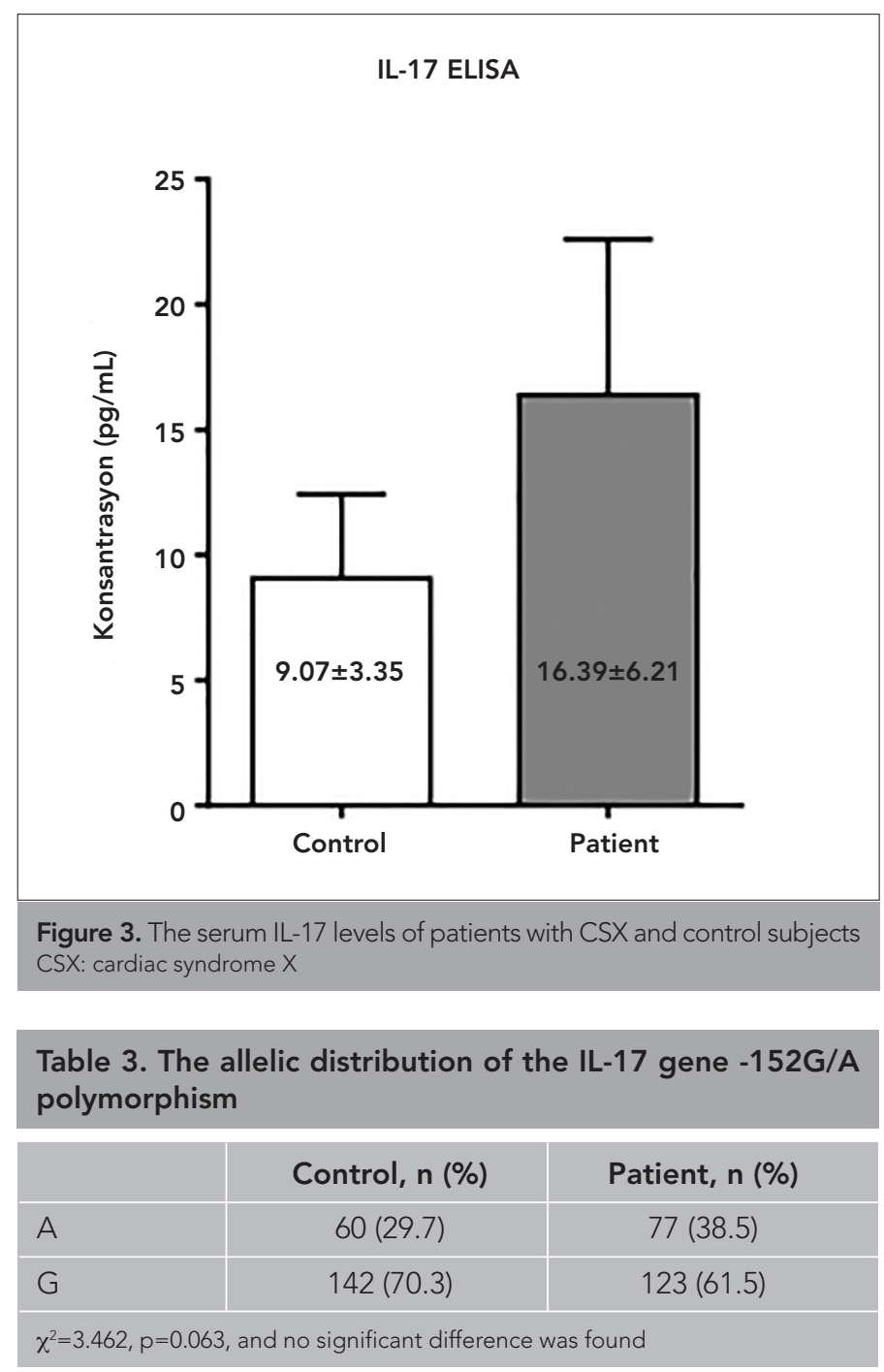

a number of chemical mediators that are found in the plasma and that are released from the cells (13). During the inflammatory response, some endogenous mediators, such as nitric oxide, platelet-activating factor, and cytokines, are synthesized from membrane phospholipids, when necessary (14).

IL-17, which has a significant proinflammatory property, may be involved in the pathogenesis of CSX $(6,15)$. It is mainly a cytokine secreted from T cells; however, it is also known to be secreted from macrophages, dendritic cells, and natural killer cells. Production of proinflammatory cytokines, chemokines, cell adhesion molecules, and growth factors can be triggered by IL-17 (6). IL-17

Table 4. The demographic information of patients with CSX and the control group

\begin{tabular}{|l|c|c|c|}
\hline Age & $\begin{array}{c}\text { Patients with } \\
(\mathbf{n}=100)\end{array}$ & $\begin{array}{c}\text { CSX Control } \\
\text { subjects (n=101) }\end{array}$ & $\mathbf{p}$ \\
\hline Female/male & 54.67 & 49.23076923 & $<0.001$ \\
\hline BMI & $71 / 29$ & $55 / 49$ & 0.007 \\
\hline HT, n (\%) & 25.028 & 24.87980769 & 0.641 \\
\hline DM, n (\%) & $43(43)$ & $12(11.5)$ & $<0.001$ \\
\hline FH, n (\%) & $32(32)$ & 0 & \\
\hline Smoking, $n(\%)$ & $31(31)$ & $15(14.4)$ & 0.004 \\
\hline Drug therapy, $n(\%)$ & & $25(24)$ & 0.021 \\
\hline BB & $16(16)$ & $7(6.7)$ & 0.036 \\
\hline CCB & $20(20)$ & $5(4.8)$ & \\
\hline ACEI/ARB & $24(24)$ & $8(7.7)$ & 0.001 \\
\hline Statin & $23(23)$ & $15(14.4)$ & 0.115 \\
\hline Effort & $62(62)$ & 0 & \\
\hline HB & $12.45 \pm 1.69$ & $13.14 \pm 1.63$ & 0.003 \\
\hline PLT & $251.69 \pm 80.26$ & $249.26 \pm 58.84$ & 0.805 \\
\hline MPV & $8.66 \pm 1.33$ & $8.55 \pm 1.02$ & 0.513 \\
\hline AST & $20.35 \pm 9.50$ & $22.75 \pm 13.13$ & 0.138 \\
\hline ALT & $21.65 \pm 15.71$ & $20.58 \pm 10.83$ & 0.569 \\
\hline GGT & $23.42 \pm 12.96$ & $25.73 \pm 11.60$ & 0.181 \\
\hline Biochemistry & & & \\
\hline TG (mg/dL) & $152.23 \pm 88.09$ & $132.72 \pm 64.27$ & 0.071 \\
\hline TC (mg/dL) & $199.18 \pm 37.60$ & $200.60 \pm 34.49$ & 0.778 \\
\hline LDL (mg/dL) & $119.58 \pm 34.08$ & $120.43 \pm 29.34$ & 0.848 \\
\hline HDL (mg/dL) & $48.15 \pm 11.56$ & $46.58 \pm 34.21$ & 0.665 \\
\hline BModys & & & \\
\hline & & & \\
\hline
\end{tabular}

BMI: body mass index; HT: hypertension; DM: diabetes mellitus; $\mathrm{FH}$ : family history; BB: beta blocker; CCB: calcium channel blocker; ACEI/ARB: angiotensin converting enzyme inhibitor/angiotensin II receptor blocker; HB: hemoglobin; PLT: platelet count; MPV: mean platelet volume; AST: aspartate aminotransferase; ALT: alanine aminotransferase; GGT: gammaglutamyl transferase; TG: triglyceride; TC: total cholesterol; LDL: low-density lipoprotein; HDL: high-density lipoprotein 
also functions in regulating monocyte accumulation and activation in aortic tissues. IL-17A and interferon- $\gamma$, with mutual influence, stimulate some inflammatory factors, such as IL-1, IL-6, IL-8, TNF- $\alpha$, and CXCL10, thereby triggering a possible inflammatory process. These results support the role of IL-17 in the proinflammatory process (7).

Cardiac syndrome $\mathrm{X}$ is more common in women than in men. It has been observed especially in women experiencing menopausal and ovarian failure symptoms. It is more common in postmenopausal women with estrogen deficiency. Estrogen deficiency may be a trigger for CSX in women with endothelial dysfunction and/ or abnormal pain perception. It has been suggested that estrogen replacement therapy may have positive results in preventing chest pain in these female patients (16). The demographic findings of our study support the fact that CSX is more common in women.

In our study, we investigated the relationship between CSX disease and the $-152 \mathrm{G} / \mathrm{A}$ polymorphism in the promoter region of IL-17 gene by using the PCR-RFLP method in a Turkish population. As a result of genotyping using genomic DNA samples belonging to patients with CSX and healthy control subjects with similar demographic characteristics, no statistically significant difference was observed between the two groups with respect to genotype distribution $(p=0.218)$. When the IL-17 gene $-152 \mathrm{G} / \mathrm{A}$ polymorphism was analyzed with respect to allele distribution, it was found that the result was close to significant, although not significant $(p=0.063)$. Thus, in future studies, it can be predicted that a significant result with respect to the relationship between CSX disease and -152G/A polymorphism allelic distribution can be obtained via increasing the number of patients and control individuals.

At the other stage of the study, IL-17 serum levels of the patients and controls were determined by the ELISA method. The statistical analysis of the results of the two groups revealed that the IL-17 levels of the patients were significantly higher than those of the control subjects. There is no study in the literature examining the serum levels of IL-17 in patients with CSX. In studies performed on individuals with inflammatory disease, IL-17 serum levels have been shown to be higher in the patient group, and these results support our study (17). Jafarzadeh et al. reported that IL-17 serum levels are significantly higher in patients with acute myocardial infarction and unstable angina than in healthy controls (18). In a study, it was shown that IL-17 levels increased in patients with hypertension, and when atherosclerosis and coronary artery disease factors were excluded, IL-17 was again reported to be a risk factor in patients with hypertension. Again in the same study, it was shown that vascular functions were preserved, and superoxide production and aortic T cell infiltration decreased in IL-17 geneextracted mice (19). According to studies conducted in China, an increase in IL-17 and Th17 levels have been reported in patients with coronary artery disease $(20,21)$. In addition, IL-17 has been shown to be effective in inflammation and the increase of CRP, which may be an indicator of cardiovascular disease; this has been shown in hepatocyte and coronary artery smooth muscle cell cultures (22). IL-17 has different properties, such as triggering the expression of proinflammatory cytokines, such as IL-6 and TNF- $\alpha$, which are involved in tissue infiltration and destruction, and chemokines, such as macrophage chemoattractant protein-1 and matrix metalloproteinases. In this way, it has been reported that IL-17 acts as a proinflammatory cytokine in various in vitro and in vivo studies (23).

In addition, HMG-CoA reductase inhibitors known to have antiinflammatory effect are known to inhibit IL-17 gene expression and secretion by T cells (24). In this context, it is evident that the use of statins in routine treatment options can prevent or decrease the findings related to inflammation in patients with CSX, whose serum levels are high and whose pathogenesis is accused of inflammation.

\section{Study Limitations}

Our study has limitations. Since the project budget is within certain limits, different polymorphisms on the IL-17 gene cannot be examined. In addition, again due to the limited budget, not being able to increase the number of patients and the number of controls can be considered as a restriction. In addition to IL-17, another limitation is the inability to study other cytokines thought to be involved in the pathogenesis of CSX, other markers such as high-sensitivity CRP and other additional markers that have been shown to play a role in the development of microvascular dysfunction, vascular inflammation, and endothelial dysfunction. Moreover, another limitation is the diagnosis of CSX by coronary angiography. Because coronary angiography is a lumenography, it is insufficient to identify outwardly eccentric plates that do not narrow the coronary lumen. Therefore, the fact that intracoronary imaging methods, such as intravascular ultrasonography and optical coherence tomography, cannot be used in our study may be interpreted as another limitation.

\section{CONCLUSION}

In our study, although there was no statistical relationship between IL-17 -152G/A polymorphism and CSX disease, the serum levels of IL-17 were significantly higher in patients with CSX than in healthy controls. Therefore, we believe that various polymorphisms seen on the gene encoding the cytokine IL-17, which is known to play a role in endothelial dysfunction and inflammatory diseases responsible for the pathogenesis of CSX, may be a marker for CSX disease. To better elucidate the relationship between these polymorphisms on the IL-17 gene and CSX disease, more extensive studies can be conducted by including different polymorphisms that may cause conformational changes in cytokines or by increasing the number of samples.

Ethics Committee Approval: Ethics committee approval was received for this study from the Ethics Committee of İstanbul University CerrahpaşaCerrahpaşa School of Medicine (Approval no. 35453).

Informed Consent: Written informed consent was obtained from patients who participated in this study.

Peer-review: Externally peer-reviewed.

Author Contributions: Concept - Y.G.Ö., B.Ö., B.D.; Design - Y.G.Ö., B.Ö.; Supervision - D.Ö., A.G.A.; Resources - B.Ö., D.Ö., B.D.; Data Collection and/or Processing - Y.G.Ö., D.Ö., B.D.; Analysis and/or Interpretation - C.K., B.D., A.G.A.; Literature Search - Y.G.Ö., D.Ö., C.K..; Writing Manuscript - Y.G.Ö., B.Ö., D.Ö.; Critical Review - B.D., A.G.A.

Conflict of Interest: The authors have no conflict of interest to declare. 
Financial Disclosure: The study was supported by the Scientific Research Projects of Istanbul University (Project No.: 23172).

\section{REFERENCES}

1. Kaski JC, Rosano GM, Collins P, Nihoyannopoulos P, Maseri A, Poole-Wilson PA. Cardiac syndrome $X$ : clinical characteristics and left ventricular function. Long-term follow-up study. J Am Coll Cardiol 1995; 25: 807-14. [CrossRef]

2. Buffon A, Rigattieri S, Santini SA, Ramazzotti V, Crea F, Giardina B, et al. Myocardial ischemia-reperfusion damage after pacing-induced tachycardia in patients with cardiac syndrome X. Am J Physiol Heart Circ Physiol 2000; 279: H2627-33. [CrossRef]

3. Dierich MP, Erdei A, Huemer H, Petzer A, Stauder R, Schulz TF, et al. Involvement of complement in B-cell, T-cell and monocyte/macrophage activation. Immunol Lett 1987; 14: 235-42. [CrossRef]

4. Galle J, Quaschning T, Seibold S, Wanner C. Endothelial dysfunction and inflammation: what is the link? Kidney Int Suppl 2003: 45-9. [CrossRef]

5. Guzik TJ, Mangalat D, Korbut R. Adipocytokines - novel link between inflammation and vascular function? J Physiol Pharmacol 2006; 57: 505-28.

6. Yao Z, Painter SL, Fanslow WC, Ulrich D, Macduff BM, Spriggs MK, et al. Human IL-17: a novel cytokine derived from T cells. J Immunol 1995; 155: 5483-6.

7. Aggarwal S, Gurney AL. IL-17: prototype member of an emerging cytokine family. J Leukoc Biol 2002; 71: 1-8.

8. Task Force Members, Montalescot G, Sechtem U, Achenbach S, Andreotti F, Arden C, et al. 2013 ESC guidelines on the management of stable coronary artery disease: the Task Force on the management of stable coronary artery disease of the European Society of Cardiology. Eur Heart J 2013; 34: 2949-3003. [CrossRef]

9. Michaelides A, Ryan JM, VanFossen D, Pozderac R, Boudoulas $H$. Exercise-induced QRS prolongation in patients with coronary artery disease: a marker of myocardial ischemia. Am Heart J 1993; 126: 1320-5. [CrossRef]

10. Kemp HG, Kronmal RA, Vlietstra RE, Frye RL. Seven year survival of patients with normal or near normal coronary arteriograms: a CASS registry study. J Am Coll Cardiol 1986; 7: 479-83. [CrossRef]

11. Anderson TJ. Assessment and treatment of endothelial dysfunction in humans. J Am Coll Cardiol 1999; 34: 631-8. [CrossRef]
12. Recio-Mayoral A, Rimoldi OE, Camici PG, Kaski JC. Inflammation and microvascular dysfunction in cardiac syndrome $X$ patients without conventional risk factors for coronary artery disease. JACC Cardiovasc Imaging 2013; 6: 660-7. [CrossRef]

13. Lentsch $A B$, Ward PA. Regulation of inflammatory vascular damage. J Pathol 2000; 190: 343-8. [CrossRef]

14. Medzhitov R. Origin and physiological roles of inflammation. Nature 2008; 454: 428-35. [CrossRef]

15. Kawaguchi M, Adachi M, Oda N, Kokubu F, Huang SK. IL-17 cytokine family. J Allergy Clin Immunol 2004; 114: 1265-73. [CrossRef]

16. Kaski JC. Overview of gender aspects of cardiac syndrome X. Cardiovasc Res 2002; 53: 620-6. [CrossRef]

17. Gullick NJ, Abozaid HS, Jayaraj DM, Evans HG, Scott DL, Choy EH, et al. Enhanced and persistent levels of interleukin (IL)-17+ CD4 ${ }^{+} \mathrm{T}$ cells and serum IL-17 in patients with early inflammatory arthritis. Clin Exp Immunol 2013; 174: 292-301. [CrossRef]

18. Jafarzadeh A, Esmaeeli-Nadimi A, Nough H, Nemati M, Rezayati MT Serum levels of interleukin (IL)-13, IL-17 and IL-18 in patients with ischemic heart disease. Anadolu Kardiyol Derg 2009; 9: 75-83.

19. Madhur MS, Lob HE, McCann LA, Iwakura Y, Blinder Y, Guzik TJ, et al. Interleukin 17 promotes angiotensin Il-induced hypertension and vascular dysfunction. Hypertension 2010; 55: 500-7. [CrossRef]

20. Hashmi S, Zeng QT. Role of interleukin-17 and interleukin-17induced cytokines interleukin-6 and interleukin-8 in unstable coronary artery disease. Coron Artery Dis 2006; 17: 699-706. [CrossRef]

21. Cheng X, Yu X, Ding YJ, Fu QQ, Xie JJ, Tang TT, et al. The Th17/Treg imbalance in patients with acute coronary syndrome. Clin Immunol 2008; 127: 89-97. [CrossRef]

22. Patel DN, King CA, Bailey SR, Holt JW, Venkatachalam K, Agrawal $A$, et al. Interleukin-17 stimulates $C$-reactive protein expression in hepatocytes and smooth muscle cells via p38 MAPK and ERK1/2dependent NF-kappaB and C/EBPbeta activation. J Biol Chem 2007; 282: 27229-38. [CrossRef]

23. Kolls JK, Linden A. Interleukin-17 family members and inflammation. Immunity 2004;21:467-76. [CrossRef]

24. Zhang X, Jin J, Peng X, Ramgolam VS, Markovic-Plese S. Simvastatin inhibits IL-17 secretion by targeting multiple IL-17-regulatory cytokines and by inhibiting the expression of IL-17 transcription factor RORC in CD4+ lymphocytes. J Immunol 2008; 180: 6988-96. [CrossRef] 